\title{
Décadrages Décadrages
}

cinéma, à travers champs Cinéma, à travers champs

6 | 2005

Train et cinéma

\section{Editorial}

\section{François Bovier et André Chaperon}

\section{OpenEdition}

Journals

Édition électronique

URL : https://journals.openedition.org/decadrages/478

DOI : $10.4000 /$ decadrages.478

ISSN : 2297-5977

\section{Éditeur}

Association Décadrages

\section{Édition imprimée}

Date de publication : 10 octobre 2005

Pagination : 4-6

ISBN : 978-2-9700582-2-9

ISSN : 2235-7823

Référence électronique

François Bovier et André Chaperon, «Editorial », Décadrages [En ligne], 6 | 2005, mis en ligne le 20 janvier 2014, consulté le 29 mars 2022. URL : http://journals.openedition.org/decadrages/478 ; DOI : https://doi.org/10.4000/decadrages.478

(B) Décadrages 


\section{Editorial}

A - Une fois de plus, ils ont remis sur le métier la problématique du train au cinéma, s'engageant sur des voies déjà par trop balisées.

B - Il se pourrait bien en effet qu'il ne soit plus guère possible d'extraire encore de cette matière quelque combustible apte à produire une avancée dans quelque champ de savoir que ce soit. Filons bien épuisés que ceux du train, aussi bien comme dispositif que comme motif.

A - Le train est définitivement entré en gare, dans le cadre de l'écran ainsi que dans celui des études théoriques et historiques, sans même prendre en compte la geste maintes fois contée de la conquête de l'espacetemps par cette mécanique bien huilée.

B - Ne pourrait-on pas au moins leur reconnaître le mérite de s'être engagés dans une voie de traverse bifurquant d'avec ces chemins qui ne mènent nulle part?

Hésitant à abonder dans le sens de son interlo-

cuteur, le premier décida d'entrer dans le vif du dossier pour en éprouver la solidité.

A - Faisons défiler devant nous les différents objets qu'ils se sont donnés. Pure incongruité tératologique par exemple que d'avoir abouté de la sorte Richard Serra et Ken Jacobs.

в - Ne voyez-vous donc pas que Ken Jacobs a lui-même déjà opéré une greffe "expérimentale» sur le cinéma des premiers temps, actualisant les virtualités invues de ce dernier. Jacobs et Serra mettent à jour deux modalités de perception ferroviaire opposées : l'un mise sur la désorientation du spectateur, l'autre sur le «surcadrage» de l'espace à travers le modèle du pont tournant. L'intervention de Livoi Belloï, en position de surplomb théorique, permet d'encadrer historiquement ces démarches expérimentales. Quelque vingt ans après la reprise de la notion eisensteinienne du cinéma des attractions dans le champ des études des films des premiers temps, Belloï propose le concept de vue attentatoire, considérant le train comme un projectile lancé aussi bien dans l'espace qu'en direction du spectateur.

Sur la voie nosographique, Mireille Berton analyse la manière dont le discours médical hystérise le dispositif cinématographique envisagé comme le dernier symptôme en date de la modernité; en effet, au début du siècle, l'agitation corpusculaire induite par le tressautement ferroviaire 


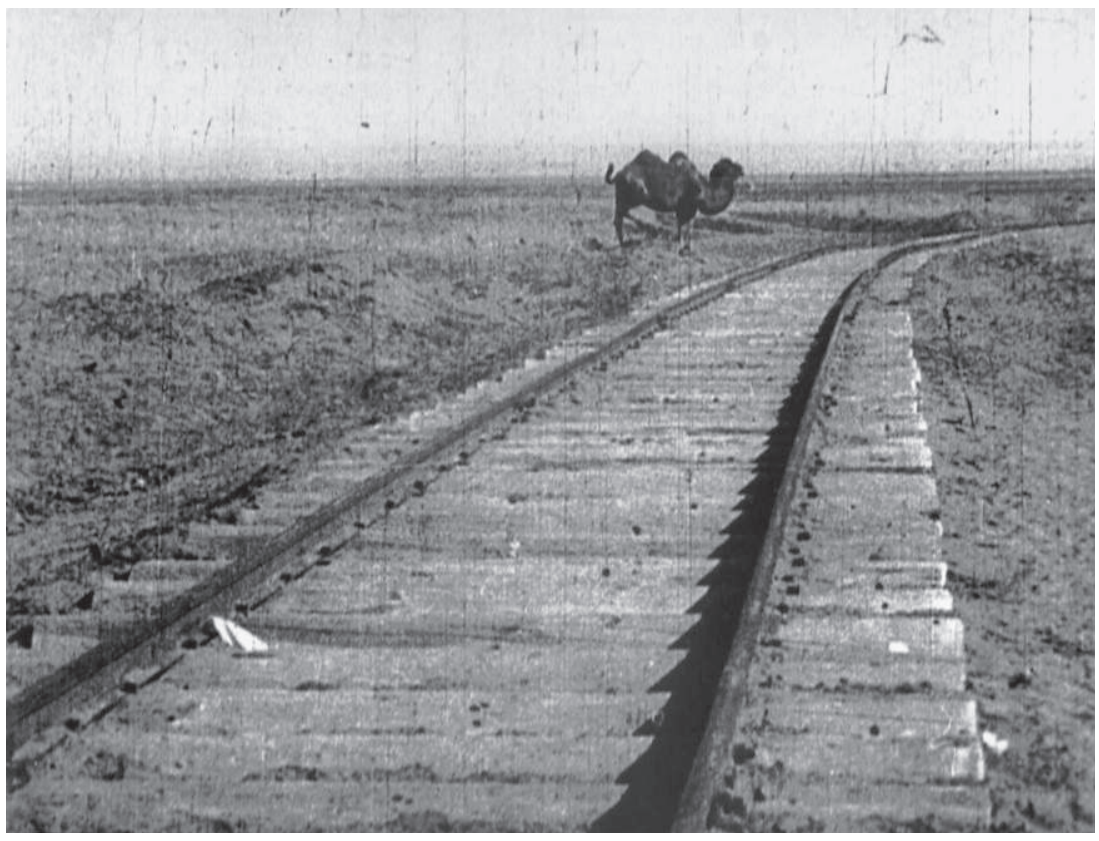

TURKSIB (VICTOR TOURINE, URSS, 1929) 
est montée en parallèle avec les dérèglements psychophysiologiques consécutifs au scintillement de la projection.

A - Saute intempestive que de raccorder au sein d'un même dossier l'imaginaire vernien du train lunaire aux véhicules lancés à grande vitesse dans les films de poursuite contemporains.

B - Tous deux participent pourtant à l'histoire des représentations, l'analyse de Courcoux s'inscrivant dans le versant américain des études culturelles. Par ailleurs, Albera rappelle que pour Gance il n'y avait aucune contradiction à mixer structure feuilletonesque et montage symphonique, romance sirupeuse et morceaux de bravoure avantgardiste. Albera joue Pierre Hamp, la source du film de Gance, contre la novellisation de Canudo résolvant, malgré son point de vue critique qui est le plus souvent retenu, la non contradiction gancienne en faveur du mélodrame.

La mise en réseau de la rubrique suisse et du dossier thématique témoigne bien de la productivité de ce motif et de ce dispositif. Le train apparaît dès lors comme véhicule privilégié pour mettre en valeur le paysage suisse, à travers le cache mobile de la fenêtre qui se déplace le long des chemins de fer. L'article de Cosandey met bien en évidence l'isomorphisme au tournant du siècle entre le quadrillage du paysage par les guides touristiques et le catalogage cinématographique des principales attractions naturelles. Comme le montre Jaques, à un stade ultérieur du développement de la production cinématographique, le cinéma industriel en tant que genre est instrumentalisé par les CFF comme le moyen de promotion le plus approprié pour prendre panoramiquement la mesure du paysage suisse.

Se rabattant sur ce qui, dans ce numéro, se soustrait à l'engrenage ferroviaire, le premier fait saillir l'intérêt des pièces hors dossier qui anticipent l'actualité.

A - Ils gagnent en pertinence dès lors qu'ils donnent la parole à Humbert et Penzel, cinéastes suisse et germanique qui ont consacré plusieurs documentaires de création à des artistes, dont le dernier au saxophoniste Yusef Lateef. Ils explorent la même voie en s'attachant à la dernière œuvre de Cattin et Kostomarov, le premier étant suisse, le second russe, qui auscultent la réalité postsoviétique d'aujourd'hui, revivifiant ainsi le cinéma direct.

B - Brother Yusef et Vivre en paix ne tarderont d'ailleurs pas à sortir au cinéma Spoutnik de Genève. 